\title{
Hematodermic Tumour Resembling a Battered Child Syndrome
}

Antonio Ruggiero ${ }^{1 *}$, Palma Maurizi ${ }^{1}$, Stefano Mastrangelo ${ }^{1}$, Giorgio Attina ${ }^{1}$, Daniela Rizzo ${ }^{1}$, Riccardo Riccardi ${ }^{1}$

${ }^{1}$ Division of Pediatric Oncology, Catholic University of Rome, Largo A. Gemelli 8, Rome 00168, Italy.

*Correspondending Author: Antonio Ruggiero, MD, Catholic University of Rome, Italy. Phone: + 39-06-3058203; Fax: + 39-063052751; E-mail: antonio.ruggiero@unicatt.it.

\section{ABSTRACT}

Background: Hematodermic tumours are rare neoplasms, of the hematolymphoid system, consisting of a heterogeneous group of aggressive course tumours. Early tumor recognition may allow physicians to avoid misdiagnosis.

Objectives: To report a case occurring in an eight-year-old male child that was initially diagnosed as a haematoma secondary to child abuse.

Results: A child, with an initially misdiagnosed hematodermic tumour located on the posterior region of the left thigh underwent, a few months after clinical onset, a skin biopsy of the affected tissue for histopathology which was diagnostic for CD4+/CD56+ hematodermic tumour.

Conclusion: Although hematodermic tumors are relatively rare, clinicians should broaden the differential diagnosis, to include malignancies, when unexplained clinical pictures are brought to their attention.

\section{GOPEN ACCESS}

DOI: $10.20900 / m o .20160020$

Received: July 08, 2016

Accepted: September 10, 2016

Published: October 25, 2016

Copyright: $\odot 2016$ Cain et al. This is an open access article distributed under the terms of the Creative Commons Attribution License, which permits unrestricted use, distribution, and reproduction in any medium, provided the original author and source are credited.

Key Words: Hematodermic tumour; Battered child; Chemotherapy

\section{INTRODUCTION}

We describe a child with a primary CD4+/CD56+ hematodermic tumour characterized by a skin lesion with a bruise-like aspect. It was initially 
diagnosed as a thigh haematoma secondary to child abuse.

\section{CASE REPORT}

The child presented to his local hospital with a 5-month history of haematoma located on the posterior left thigh. He was initially investigated for a bleeding diathesis, but coagulation screening tests, and a haematoma drainage, were inconclusive. The physicians inferred a battered child syndrome and treated the patient conservatively.

Four months later, he was admitted for further evaluation. On examination, a the left posterior thigh ecchymosis and multiple purple lesions on both legs were present (Fig. 1. a-b). During his hospital stay, a left groin lymph node enlarged. He underwent a lymph node, and cutaneous, biopsy which were diagnostic for a CD4+/CD56+ hematodermic tumour. A bone marrow aspirate was negative for neoplastic infiltration. The patient was treated with chemotherapy, went into remission and the haematoma gradually disappeared. Two years after initial presentation, he is well and disease free.

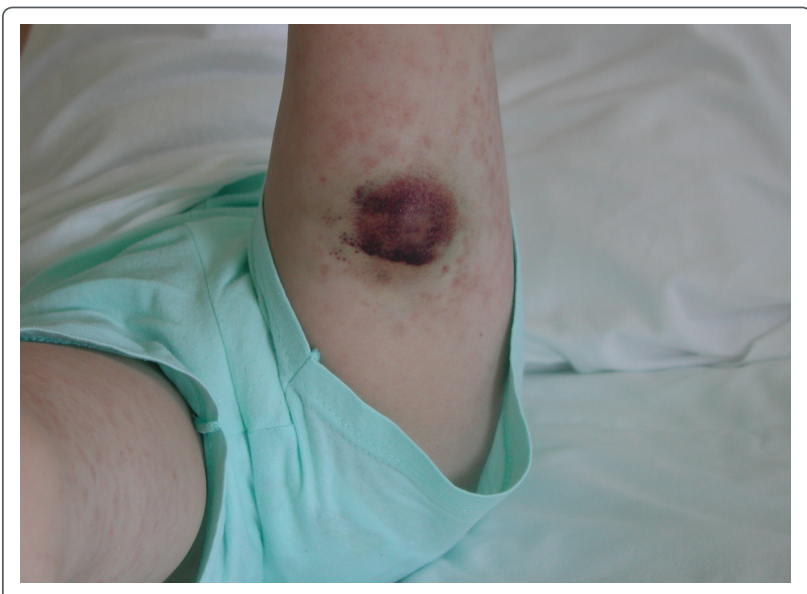

Fig. 1 a



Fig. 1 b

\section{DISCUSSION}

The disease spectrum of CD4+/CD56+ hematodermic tumour is expanding with only a few paediatric cases documented ${ }^{[1,2,3]}$. It has been described as a distinct clinicopathologic entity, with an aggressive course and a poor outcome. CD4+/CD56+ hematodermic malignancies are rare entity in the hematolymphoid system. They consist of neoplasms with a high incidence of cutaneous involvement and a risk of rapid leukaemic dissemination. These neoplasms mainly involve skin at the initial diagnosis with often indolent presentation, but later manifest a speedy, and aggressive progression, which is usually quickly fatal [4]

Awareness of this particular clinical presentation may allow physicians to avoid a misdiagnosis. In our case, the initial erroneous conclusion delayed a correct diagnosis and triggered an extensive social service investigation which exonerated the child's parents of any suspicion of child abuse.

Diagnosing a CD4+/CD56+ hematodermic tumour may be complex, especially when an isolated extramedullary involvement is the presenting sign $[5,6]$. Since clinical findings may be nonspecific and histopathology is only suggestive, misdiagnosis is likely. Clinicians should broaden the differential diagnosis, to include malignancies, when unexplained or poorely-defined clinical pictures are provided. Early recognition and appropriate treatment are essential to improving a chance to cure these patients.

\section{CONFLICT OF INTEREST STATEMENT}

No conflict of interests and financial disclosure is present. Each author has substantially contributed to the acquisition and analysis of data.

\section{REFERENCES}

1. Imamura N, Kusunoki Y, Kawa-Ha K. Aggressive natural killer leukemia/lymphoma: report of four cases and review of the literature. $\mathrm{Br} \mathrm{J}$ Hematol. 1990; 75(1): 49-59.

2. Gniadecki R, Rossen K, Ralfkier E, Thomsen K, Skovgaard GL, Jonsson VI. CD56+ Iymphoma with skin involvement: clinicopathologic features and classification. Arch Dermatol. 2004; 140(4): 
427-436.

3. Ruggiero A, Maurizi P, Larocca LM, Arlotta A, Riccardi R. Childhood CD4+/CD56+ hematodermic neoplasm: case report and review of the literature. Haematologica. 2006; 91(12 Suppl): ECR48.

4. Karube K, Ohshima K, Tsuchiya T, Yamaguchi T, Suefuji H, Suzumiya J, Harada M, Kikuchi M. Non-B, non-T neoplasms with lymphoblast morphology: further clarification and classification. Am J Surg Pathol. 2003; 27(10): 1366-1374.

5. Kwong YL. Natural killer-cell malignancies: diagnosis and treatment. Leukemia. 2005; 19(12): 2186-2194.

6. Jaffe ES. Classification of natural-killer (NK) and NK-like T-cell malignancies. Blood. 1996; 87(4): 1207-1210. 